Научная статья

УДК 338.2

DOI 10.18101/2304-4446-2021-3-46-54

\title{
ОБУЧЕНИЕ ПРОЕКТНОМУ УПРАВЛЕНИЮ МУНИЦИПАЛЬНЫХ СЛУЖАЩИХ РЕСПУБЛИКИ БУРЯТИЯ
}

\section{(c) Дугарова Альбина Аюшеевна}

кандидат политических наук, доцент albinabur@mail.ru

\section{(C) Мункуева Ирина Сергеевна}

кандидат экономических наук, доцент mishka81@yandex.ru

\section{(C) Родионова Дарья Николаевна}

кандидат социологических наук, доцент rodar79@mail.ru

Бурятский государственный университет имени Доржи Банзарова Россия, 670000, г. Улан-Удэ, ул. Смолина, 24a

Аннотация. Перед органами местного самоуправления современные реалии диктуют особые условия и задачи в области разработки программ развития, формирования проектных компетенций у муниципальных служащих. В настоящее время утвержден целый комплекс методических рекомендаций по внедрению проектного управления, установлены порядок и функциональная структура организации проектной деятельности.

Материал, изложенный в статье, представляет собой результаты совместной деятельности органов власти и преподавательского состава Института экономики и управления Бурятского государственного университета имени Д. Банзарова по применению технологий проектного обучения на примере разработки проектов для муниципальных образований республики. Анализируемая программа обучения направлена на повышение эффективности профессиональной служебной деятельности у муниципальных служащих путем изучения основ проектного управления, понимания методики ведения проектной деятельности и получения практических навыков реализации проектов. Авторы отмечают, что усиление вектора проектной направленности в подготовке муниципальных служащих связано с потребностью экономики в особой модели специалиста, умеющего систематизировать большой объем разнообразной информации, владеющего навыками организации командной деятельности, анализирующего принципиальные технические решения и технологии, предлагаемые для реализации проектов.

Ключевые слова: проектное управление, проектная компетенция, органы власти, государственное и муниципальное управление, повышение квалификации

\section{Для цитирования}

Дугарова А. А., Мункуева И. С., Родионова Д. Н. Обучение проектному управлению муниципальных служащих Республики Бурятия // Вестник Бурятского государственного университета. Экономика и менеджмент. 2021. № 3. С. 46-54. 
А. А. Дугарова, И. С. Мункуева, Д. Н. Родионова. Обучение проектному управлению муниципальных служащих Республики Бурятия

\section{Введение}

Стратегические цели, обозначенные Российской Федерацией на ближайшее десятилетие, требуют новых инструментов и механизмов ${ }^{1}$. К таким инструментам относится внедрение проектного менеджмента в сферу публичного управления на всех уровнях власти. Предоставление качественных услуг, создание современной инфраструктуры, ориентация на конкретный результат, а не «на освоение бюджетных денег», требуют переосмысления организационноуправленческих процессов, а также изменения философии государственных и муниципальных служащих в плане отхода от традиционного стиля управления.

Для достижения целей национальных проектов необходимо создать нормативную правовую основу, организационную структуру на региональном и муниципальном уровне, подготовить профессиональные кадры. От государственных и муниципальных служащих требуется владение профессиональными компетенциями в области проектного управления.

Обзор практики внедрения проектного управления в регионах свидетельствует, что в субъектах Российской Федерации этот процесс идет неравномерно. Как отмечают многие исследователи, проект и проектное управление не являются совершенно новыми инструментами для государственного управления России [3]. Например, строительство уникальных сооружений, таких как СаяноШушенская ГЭС, Гусиноозерская ГРЭС и многие другие, является проектом. В чем же сложность внедрения того, что в принципе было известным? Затруднения возникают как раз в переходе с традиционного ведомственного управления на проектное управление, т. е. в организации эффективного взаимодействия между участниками проекта по поводу планирования, организации работ, контроля ресурсов, направленного на эффективное достижение цели проекта.

Для того чтобы переломить ситуацию, необходимо обучение основам проектного подхода всех государственных и муниципальных служащих [2]. Должно быть общее понимание реформ государственного управления на современном этапе. Для тех, кто непосредственно будет участвовать в разработке и реализации проекта на всех этапах его жизненного цикла, необходимо специальное обучение, сертификация, умение работать в команде и т. д.

\section{Организация проектной деятельности в Республике Бурятия}

Начиная с 2016 г. на федеральном уровне приняты основополагающие документы по организации проектного управления: Указ Президента Российской Федерации от 30 июня 2016 г. № 306 «О Совете при Президенте Российской Федерации по стратегическому развитию и приоритетным проектам», Указ Президента Российской Федерации от 07.05.2018 № 204 «О национальных целях и стратегических задачах развития Российской Федерации на период до 2024 года», Постановление Правительства Российской Федерации от 31.10 .2018 № 1288 «Об организации проектной деятельности в Правительстве Российской Федерации», а также методические указания по разработке национальных проектов (программ), по организации проектной деятельности в федеральных органах исполнительной

\footnotetext{
${ }^{1}$ Единый план по достижению национальных целей развития Российской Федерации до 2024 года. URL: http://static.government.ru/media/files/j8IV1FkssLpUqI89JCXZ2mLiIiLEn 7H8.pdf.
} 
власти и др., приняты государственные отраслевые стандарты (ГОСТы): руководство по проектному менеджменту, управление проектом, управление программой, управление портфелем. Действует Центр проектного менеджмента РАНХиГС, который наделен функциями центра компетенций проектного управления. Таким образом, можно констатировать, что на федеральном уровне создана организационная и нормативная основа проектного управления.

Рассмотрим, что сделано по этому направлению в Республике Бурятия. В 2017 г. в Республике Бурятия опубликован Указ Главы РБ № 141 от 19 июля 2017 года «О Совете при Главе Республики Бурятия по проектному управлению в Республике Бурятия», принято Постановление Правительства Республики Бурятия от 21.09.2017 № 469 «Об организации проектной деятельности в Правительстве Республики Бурятия» ${ }^{1}$. Организован Совет по проектному управлению, координатором проектной деятельности в республике является Первый заместитель Председателя Правительства Республики Бурятия, кураторы регионального проекта утверждаются координатором проектной деятельности. Проектный офис Республики Бурятия обеспечивает общую координацию реализации региональных проектов.

В 2017 г. организован республиканский проектный офис по развитию монопрофильных муниципальных образований для реализации мероприятий направления «Моногорода»», в состав которого входят главы Кабанского, Селенгинского, Закаменского, Мухоршибирского районов и руководители моногородов Северобайкальск, Гусиноозерск, Закаменск, городских поселений «Селенгинское», «Каменское» и сельского поселения «Саганнурское» ${ }^{2}$.

В муниципальных образованиях республики создаются проектные офисы, так, в 2018 г. в Селенгинском районе создан муниципальный проектный офис. В 2020 г. в администрации города Улан-Удэ организован проектноаналитический комитет для совершенствования проектной деятельности ${ }^{3}$.

\footnotetext{
${ }^{1}$ О Совете при Главе Республики Бурятия по проектному управлению в Республике Бурятия: указ Главы РБ № 141 от 19 июля 2017 года. URL: https://docs.cntd.ru/document/450280763 (дата обращения: 10.06.2021). Текст: электронный; Об организации проектной деятельности в Правительстве Республики Бурятия: постановление Правительства Республики Бурятия от 21.09.2017 № 469. URL: https://docs.cntd.ru/document/450346225 (дата обращения: 10.06.2021). Текст: электронный.

${ }^{2}$ Об образовании республиканского проектного офиса по развитию монопрофильных муниципальных образований (моногородов) Республики Бурятия: распоряжение Правительства Республики Бурятия от 31 марта 2017 года №179-p. URL: https://docs.cntd.ru/document/446176643 (дата обращения: 10.06.2021). Текст: электронный.

3 О создании муниципального проектного офиса муниципального образования «Селенгинский район»: распоряжение АМО «Селенгинский район» от 2 октября 2018 г. № 368. URL: https://admselenga.ru/kpert/proektnyj-ofis (дата обращения: 10.06.2021). Текст: электронный; Об утверждении Положения о Проектно-аналитическом комитете Администрации г. Улан-Удэ: постановление Администрации г. Улан-Удэ от 13.07.2020 № 148 г. Улан-Удэ. URL: https://docs.cntd.ru/document/570861167 (дата обращения: 20.06.2021). Текст: электронный; Об организации проектной деятельности в Администрации г. Улан-
} 
А. А. Дугарова, И. С. Мункуева, Д. Н. Родионова. Обучение проектному управлению муниципальных служащих Республики Бурятия

Государственные и муниципальные служащие республики обучаются основам проектного управления, как с участием приглашенных специалистов из РАНХиГС и других организаций, так и с выездом в регионы для изучения передового опыта. Так, в 2021 г. в БГСХА прошли профессиональную переподготовку представители кадрового резерва муниципальных образований по теме «Современное управление развитием территории муниципальных образований». При ВСГУТУ создан региональный центр сертификации проектного управления РМ Стандарт в Республике Бурятия. С 2020 г. Проектным офисом Республики Бурятия ставится вопрос об организации Центра компетенций проектной деятельности, который обеспечивал бы внедрение и обучение проектным механизмам, а также комплексное и экспертное сопровождение проектной деятельности в государственном секторе и способствовал бы формированию единой системы обмена лучшими практиками проектного подхода.

В Бурятии в 2020 г. реализуется 50 региональных проектов в рамках национальных проектов: Обеспечение качественного нового уровня развития инфраструктуры культуры («Культурная среда»); Создание условий для реализации творческого потенциала нации («Творческие люди»); Цифровизация услуг и формирование информационного пространства в сфере культуры («Цифровая культура»); Информационная инфраструктура; Кадры для цифровой экономики; Информационная безопасность; Цифровые технологии; Цифровое государственное управление; Современная школа; Успех каждого ребенка; Поддержка, семей имеющих детей; Цифровая образовательная среда; Учитель будущего.

В республике создана инфраструктура проектного управления, однако она требует дальнейшего совершенствования. Те проекты, которые реализуются по национальным проектам, в отдельных случаях требуют доработок. Так, при строительстве новой школы в с. Клюевка Кабанского района в проекте не было предусмотрено строительство подъездной дороги, благоустройство прилегающей территории, что требует дополнительных усилий и средств. Это один из примеров, «не проектного подхода», когда важным становится сдача объекта, а не его эффективная эксплуатация, к сожалению, таких примеров достаточно. Именно поэтому необходимо широкое внедрение, освещение сути проектного менеджмента для управленцев.

\section{Из опыта обучения проектному управлению муниципальных служащих Республики Бурятия}

В основе процессов обучения по подготовке муниципальных служащих в области проектного управления заложена концепция проектно-ориентированного обучения. Целью проектного обучения является формирование интереса у обучающихся к реализации действий, направленных на ликвидацию проблем через проектную деятельность, где также важную роль играет мотивационная составляющая в виде активизации самостоятельной деятельности и творческой активности. В систему обучения заложена технология «обучение действием». В образовательном плане проектное обучение обеспечивает муниципальным служащим приобретение способности самостоятельного овладения знаниями и умениями,

Удэ: постановление Администрации г. Улан-Удэ от 25.11.2019 № 359. URL: https://docs.cntd.ru/document/561626700 (дата обращения: 20.06.2021). Текст: электронный. 
их углубление и закрепление, развитие умений самостоятельно конструировать собственные знания, а также хорошо ориентироваться в информационном пространстве. У таких специалистов, освоивших навыки проектной деятельности, формируется проектная компетентность, что способствует развитию их креативности.

В процессе обучения особое внимание уделяется формированию проектной культуры, которая является важным элементом системы проектного управления. Развитие проектной культуры идет как через практический опыт, так и через теоретическое обучение, в результате которого формируется проектная грамотность - один из важнейших ее компонентов.

Значимость курса обусловлена востребованностью использования проектного принципа в органах муниципального управления для повышения эффективности деятельности, соблюдения и сокращения сроков, рационального использования ресурсов и устранения барьеров внутриведомственного и межведомственного взаимодействия за счет использования единых подходов проектного управления. Программа обучения имеет прикладную направленность и формирует у муниципальных служащих необходимые практические навыки проектного управления (осуществление ранжирования проектов, подготовка документов на этапе инициации, работа с командой проекта, составление ленточных и сетевых графиков реализации проектов, работа с картой рисков и т. д.).

В последнее время в регионах достаточно активно проходит обучение муниципальных служащих, что регулярно отражается на официальных сайтах. В этом плане деятельность Института экономики и управления Бурятского государственного университета также направлена на формирование компетентностной модели в области проектного управления. Начиная с 2019 г. Институтом проведено обучение 37 муниципальных служащих по теме «Управление проектами на муниципальном уровне: структура, процессы, практика применения». В 2020 г. по теме «Управление проектами в органах государственной и муниципальной власти» прошли обучение 43 главы муниципальных образований, 31 муниципальный служащий. Обучение проектному управлению проходило в рамках подготовки к республиканским конкурсам «Лучший муниципальный служащий», «Лучший глава городского, сельского поселения».

По программе обучения в университете разработан комплекс учебнометодических материалов с учетом нормативной правовой базы республики, рабочие тетради, методические указания по защите проектов и презентаций. Материалы слушателям предоставлены на портале электронного обучения e-bsu. Были проведены занятия по темам: «Основы проектного управления», «Постановка цели. Методология SMART», «Разработка концепции проекта на этапе инициации. Умное целеполагание проекта», «Проектные роли и организационная структура управления проектной деятельностью», «Планирование проекта. Декомпозиция работ», «Управление рисками», «Оценка опыта проектного управления в системе образования Республики Бурятия» и другие.

B 2020 г. обучение проводилось на платформе Zoom. По итогам занятий к каждому слушателю был прикреплен куратор из числа преподавателей университета. В сентябре прошел очный практикум по работе над проектами, также были проведены мастер-классы по публичным выступлениям, презентациям. 
А. А. Дугарова, И. С. Мункуева, Д. Н. Родионова. Обучение проектному управлению муниципальных служащих Республики Бурятия

В университете сформирована команда из преподавателей-кураторов, осуществляющих консультационную и экспертную поддержку проектов с постоянно действующим информационным каналом связи в мессенджерах.

В ноябре 2020 г. на конкурс «Лучший глава городского, сельского поселения» документы представили 31 глава. Конкурс проходил в онлайн-формате. Проекты были направлены на развитие сельского хозяйства, туризм, создание комфортной среды в поселениях, решение социальных вопросов. Широкий интерес у членов конкурсной комиссии вызвали такие проекты, как: «Создание предприятия по сбору и переработке дикоросов и плодово-ягодных культур», «Создание условий для самозанятости граждан села Выдрино», «Отходы в доходы: производство пилетов», Социальный проект «Фестиваль 4 лапы», «Строительство мемориала Памяти», «Создание туристического комплекса "Усадьба рыбака-старообрядца" в с. Кардон», «Агротур в Большую Кудару», «Боргойская баранина как бренд Республики Бурятия» и др. Министерство сельского хозяйства и продовольствия Республики Бурятия, Гарантийный фонд Республики Бурятия, Центр предпринимательства «Мой бизнес», представители АСИ в Бурятии намерены помочь дальнейшему продвижению проектов.

Сравнивая проекты участников конкурса «Лучший муниципальный служащий» 2019 и 2020 гг., можно отметить, что тематика проектов, проработка их стали более качественными. Так, например, такие проекты, как: «Семейный альбом для семей, находящихся в социально опасном положении», «Корова в стаде - деревня в догляде», «Создание “энергетических классов” на основе ресурсного взаимодействия школа - вуз - Гусиноозерская ГРЭС»; «Создание Геопортала г.Улан-Удэ и 3d-моделирование при осуществлении градостроительной деятельности», «Вовлечение жителей сельского поселения Аргада в реализацию социальных проектов» и многие другие реализовываются или находятся в стадии реализации в муниципальных образованиях.

Что дает такая форма проведения курсов повышения квалификации в рамках подготовки к конкурсу профессионального мастерства? По сравнению с обычными курсами, к которым привыкли обучающиеся, где итогом может выполнение теста или какое-либо практическое задание, здесь результатом обучения является проект. При этом проект, касающийся профессиональной деятельности главы или муниципального служащего, конкретного муниципального образования. На наш взгляд, такой подход усиливает мотивацию слушателей, конкуренцию между слушателями, и в то же время развивает умение работать в команде, навыки публичной защиты проектов.

Стандартные курсы повышения квалификации длятся 1-2 недели. Здесь обучение практически ведется на протяжении 5 месяцев.

Подготовительный этап (до 01.06.2020):

1) выработка концепции конкурса, разработка Постановления Правительства Республики Бурятия «О республиканском конкурсе Лучший глава городского, сельского поселения» ${ }^{1}$;

${ }^{1}$ O республиканском конкурсе «Лучший глава городского, сельского поселения»: постановление Правительства Республика Бурятия от 07.05.2020 № 250. URL: https://docs.cntd.ru/document/570789210 (дата обращения: 20.06.2021). Текст: электронный. 
2) разработка программы стратегической сессии в рамках курсов повышения квалификации «Управление проектами в органах государственной и муниципальной власти» с участием преподавателей Бурятского государственного университета им. Доржи Банзарова;

3) создание обучающего курса на платформе электронного обучения e.bsu.ru.

Теоретический этап (июнь - сентябрь 2020 г.):

1) проведение стратегической сессии по проектному управлению на платформе Zoom;

2) работа в личных кабинетах на e.bsu.ru.

Практический этап (сентябрь - ноябрь 2020 г.):

1) индивидуальная работа с кураторами по проекту;

2) консультации с кураторами и экспертами в мини-группах;

3) предварительная мини-презентация проектов (платформа Zoom);

4) доработка проектов, подготовка презентации проекта;

5) защита проектов в Бурятском государственном университете им. Доржи Банзарова.

Конкурсный этап (29 октября - 10 ноября 2020 г.)

1) заочный - оценка конкурсных документов конкурсной комиссией 29.10.2020 - 8.11.2020;

2) очный - самопрезентация и защита представленного конкурсного проекта (9-10 ноября 2020 г.);

3) подведение итогов конкурса.

Следует отметить, что курсы повышения квалификации, построенные в таком формате для преподавателей университета, являются своего рода проектом. Усиливается командная работа при затруднениях с проектом можно провести консультацию с коллегами, обсудить, доработать проекты совместно.

По итогам этой работы Бурятский государственный университет имени Доржи Банзарова совместно с комитетом территориального развития Администрации Главы Республики Бурятия и Правительства Республики Бурятии представил кадровую практику «Стратегическая сессия по проектному управлению и проведение конкурса «Лучший глава городского, сельского поселения Республики Бурятия» и стал номинантом конкурса «Лучшие кадровые практики и инициативы в системе государственного и муниципального управления», который проводит министерство труда и социальной защиты Российской Федерации с 2015 г.

\section{Заключение}

Обучение сотрудников проектной деятельности и повышение уровня компетенций является важным фактором для эффективного развития проектного управления в органах местного самоуправления.

В процессе обучения реализуются следующие задачи, такие как:

- обучить муниципальных служащих основным понятиям проектного управления: проект, программа, портфель проектов, управление проектами, проектное управление и т. д.;

- изучить классификацию проектов, международные и российские стандарты в управлении проектами, жизненный цикл проекта и жизненный цикл продукта проекта; 
А. А. Дугарова, И. С. Мункуева, Д. Н. Родионова. Обучение проектному управлению муниципальных служащих Республики Бурятия

- изучить процессы и функции управления проектами, основные группы процессов управления проектом: группы процессов инициации, группа процессов планирования, группа процессов организации исполнения, группа процессов контроля, группа процессов завершения проекта;

- получить практические навыки ранжирования проектов и работы на всех этапах жизненного цикла проекта: инициация проекта (подготовка паспорта проекта), планирование проекта (построение календарно-ресурсного графика), контроль исполнения, завершение проекта;

- научиться работать с проектной командой: формирование организационной структуры проекта, проектные роли, построение матрицы ответственности и т. д.

Обучение проектному управлению в рамках стратегической сессии в течение пяти месяцев с использованием электронного обучения, постоянное сопровождение проектов кураторами позволило добиться высоких результатов. Особое внимание было уделено умению представлять и защищать проекты, для этого в рамках сессии проходил очный практикум. В личных кабинетах были представлены необходимые материалы для самостоятельной работы. В ходе стратегической сессии проходил обмен опытом, активное сотрудничество глав разных районов. Представленные на конкурс проекты могут быть реализованы в муниципальных образованиях.

На ближайшее время определены следующие цели:

- последовательное наращивание компетенции участников проектной деятельности;

- реализация сложных, долгосрочных проектов;

- формирование системы мотивации участников проектной деятельности;

- запуск и реализация самостоятельных портфелей проектов;

- внедрение системы общественного сопровождения проектов на всех этапах реализации.

Также стоит выделить особо важную задачу - развитие проектной культуры в органах местного самоуправления и подведомственных учреждениях. Эта задача не только сложная, но и амбициозная. Несомненно, что на проектное управление возложены большие надежды, в том числе по реализации указа Президента России «О национальных целях и стратегических задачах развития Российской Федерации на период до 2024 года».

\section{Литература}

1. Васильев А. И., Прокофьев С. Е. Организация проектного управления в органах государственной власти // Управленческие науки. 2016. № 4. С. 44-52. Текст: непосредственный.

2. Зеленцова С. Ю. Кадровые проблемы реализации проектного управления в системе государственного и муниципального управления // Регион: системы, экономика, управление. 2019. № 1(44). С. 94-98. Текст: непосредственный.

3. Мирошниченко И. В., Шпиро Л. А. Проектное управление в государственном секторе: зарубежный опыт и российская практика // Вестник Удмуртского государственного университета. Социология. Политология. Международные отношения. 2019. Т. 3, № 3. C. 360-368. URL: https://journals.udsu.ru/sociology/article/view/4602 (дата обращения: 20.05.2021). Текст: электронный. 
4. Штурбина Н. А. Анализ условий, влияющих на эффективность подготовки кадров для управления проектами в образовании // Вестник Московского университета. Серия 20: Педагогическое образование. 2019. № 2. С. 21-31. Текст: непосредственный.

Статья поступила в редакцию 13.07.2021; одобрена после рецензирования 30.07.2021; принята к публикаџии 18.08.2021.

\section{TRAINING OF MUNICIPAL EMPLOYEES \\ OF THE REPUBLIC OF BURYATIA IN PROJECT MANAGEMENT}

Albina A. Dugarova

Cand. Sci. (Polit.), A/Prof.

albinabur@mail.ru

Irina S. Munkueva

Cand. Sci. (Econ.), A/Prof.

mishka81@yandex.ru

Darya N. Rodionova

Cand. Sci. (Sociol.), A/Prof.

rodar79@mail.ru

Dorzhi Banzarov Buryat State University

24a Smolina St., Ulan-Ude 670000, Russia

Abstract. The reality of contemporary times forces local authorities to create special conditions for the development of project competencies among municipal employees. Currently, there is a set of methodological recommendations for the implementation of project management, the procedure and functional structure for organizing project activities have been established.

The material presented in this article is the result of the joint activities of the authorities and the teaching staff of Economics and Management Institute of D. Banzarov Buryat State University on the use of project-based education technologies in the context of project developments for municipalities of the republic.

The analyzed training program is aimed at increasing the efficiency of professional service activities among municipal employees through studying the basics of project management, methods of project activities and gaining practical skills in project implementation.

We have emphasized that the strengthening of the project orientation vector in training of municipal employees is associated with the need of the economy for specialists who are able to systematize a large amount of various information, to organize team activities, and analyze the fundamental technical solutions and technologies proposed for the implementation of projects.

Keywords: project management, project competence, authorities, state and municipal management, advanced training

\section{For citation}

Dugarova A. A., Munkueva I. S., Rodionova D. N. Training of Municipal Employees of the Republic of Buryatia in Project Management. Bulletin of Buryat State University. Economy and Management. 2021; 3: 46-54 (In Russ.).

The article was submitted 13.07.2021; approved after reviewing 30.07.2021; accepted for publication 18.08.2021. 